\title{
Functional parameters of Dicer-independent microRNA biogenesis
}

\author{
JR-SHIUAN YANG, ${ }^{1,2}$ THOMAS MAURIN, ${ }^{1}$ and ERIC C. LAI ${ }^{1,3}$ \\ ${ }^{1}$ Department of Developmental Biology, Sloan-Kettering Institute, New York, New York 10065, USA \\ ${ }^{2}$ Molecular Biology Program, Weill Graduate School of Medical Sciences, Cornell University, New York, New York 10065, USA
}

\begin{abstract}
Until recently, a Dicer-class RNase III enzyme was believed to be essential for microRNA (miRNA) biogenesis in all animals. The conserved vertebrate locus mir-451 defies this expectation and instead matures by direct cleavage of its pre-miRNA hairpin via the Slicer activity of Argonaute2 (Ago2). In this study, we used structure-function analysis to define the functional parameters of Ago2-mediated miRNA biogenesis. These include (1) the requirement for base-pairing at most, but not all, positions within the pre-mir-451 stem; (2) surprisingly little influence of the 5'-nucleotide on Ago sorting; (3) substantial influence of Ago protein stoichiometry on mir-451 maturation; (4) strong influence of G:C content in the distal stem on $3^{\prime}$ resection of cleaved mir-451 substrates; and (5) the influence of hairpin length on substrate utilization by Ago2 and Dicer. Unexpectedly, we find that certain hairpin lengths confer competence to mature via both Dicer-mediated and Ago2-mediated pathways, and we show, in fact, that a conventional shRNA can traverse the Dicer-independent pathway. Altogether, these data inform the design of effective Dicerindependent substrates for gene silencing and reveal novel aspects of substrate handling by Ago proteins.
\end{abstract}

Keywords: Ago2; Dicer; microRNA

\section{INTRODUCTION}

The possibilities for reverse genetics in animal systems were revolutionized by the recognition of small interfering RNAs (siRNAs) and microRNAs (miRNAs). These related classes of short regulatory RNAs are manifestations of ancient post-transcriptional strategies for gene suppression, and they share broad requirements for Dicer RNase III enzymes for biogenesis and Argonaute proteins for target silencing (Lai 2003). The RNA interference (RNAi) pathway governs the biogenesis of siRNAs from perfectly double-stranded RNA (dsRNA), mostly from artificial substrates or selfish genetic elements but also from certain endogenous substrates (Fire et al. 1998; Tuschl et al. 1999; Zamore et al. 2000; Okamura and Lai 2008). Both exogenous and endogenous siRNAs regulate highly complementary targets via special catalytic Argonaute proteins, termed "Slicers," that are capable of efficient substrate cleavage.

On the other hand, miRNAs are typically generated from nuclear genes and are dedicated to host gene regulation (Lee et al. 1993; Reinhart et al. 2000; Flynt and Lai 2008).

\footnotetext{
${ }^{3}$ Corresponding author.

E-mail laie@mskcc.org.

Article published online ahead of print. Article and publication date are at http://www.rnajournal.org/cgi/doi/10.1261/rna.032938.112.
}

Canonical miRNA biogenesis proceeds via stepwise cleavage of primary hairpin-containing transcript by the nuclear Drosha RNase III enzyme (Lee et al. 2003), followed by cleavage of the resultant pre-miRNA hairpin by a Dicerclass RNase III enzyme (Grishok et al. 2001; Hutvagner et al. 2001; Ketting et al. 2001; Knight and Bass 2001). Besides the canonical pathway, a variety of alternative miRNA pathways have been described over the past few years, mostly comprising strategies in which other cellular ribonucleases substitute for Drosha to generate pre-miRNA hairpins (Yang and Lai 2011). The major characterized Drosha-independent pathways include splicing-derived mirtrons (Okamura et al. 2007; Ruby et al. 2007) and tailed mirtrons (Babiarz et al. 2008; Flynt et al. 2010), snoRNAderived miRNAs (Ender et al. 2008), RNaseZ-mediated miRNA biogenesis (Bogerd et al. 2010), and Integratormediated miRNA biogenesis (Cazalla et al. 2011). Regardless of biogenesis pathway, mature animal miRNAs typically regulate large networks of targets via 6-nt to 7-nt complements to the 5 ' end of the miRNA, also known as the "seed" region (Lai 2002; Lewis et al. 2003; Brennecke et al. 2005). Most miRNA targets are not sliced, but instead subject to deadenylation, mRNA decay, and/or translational suppression (Lai et al. 1998; Giraldez et al. 2006; Fabian et al. 2010; Guo et al. 2010). 
Mammalian Ago2 is the sole catalytic member (i.e., "Slicer") of the Ago1-4 clade and is thus responsible for cleavage of highly complementary targets of miRNAs and siRNAs (Liu et al. 2004; Meister et al. 2004). Ago2 actually matures perfectly complementary siRNA duplexes by cleaving the passenger strand, leaving a single-stranded guide RNA that can then regulate other targets (Matranga et al. 2005; Rand et al. 2005; Leuschner et al. 2006). Similarly, Ago 2 is capable of cleaving the passenger arm of certain wellduplexed pre-miRNA hairpins (Diederichs and Haber 2007). Recently, it was recognized that Ago2 has an obligate role in the biogenesis of the conserved vertebrate locus mir-451 (Cheloufi et al. 2010; Cifuentes et al. 2010; Yang et al. 2010). Its precursor serves as a typical Drosha/DGCR8 substrate, but the resultant pre-miRNA hairpin $(\sim 42 \mathrm{nt})$ is too short to be cleaved by Dicer and is instead loaded directly into Ago proteins. The hairpin population that enters Ago2 is then cleaved on its $3^{\prime}$ arm, which is then resected to yield a typical functional miRNA.

Knowledge of the RNAi pathway was rapidly harnessed as a platform for gene silencing across diverse eukaryotic systems. Although long dsRNA cannot be used directly in most mammalian cell types, due to activation of the interferon pathway, synthetic 21-nt siRNA duplexes can efficiently trigger specific gene silencing (Elbashir et al. 2001). This technique was broadened by the development of Pol IIIdriven short hairpin RNA (shRNA) constructs, enabling sustained silencing (Brummelkamp et al. 2002; Lee et al. 2002; Miyagishi and Taira 2002; Paddison et al. 2002; Paul et al. 2002; Sui et al. 2002), and was made more powerful by the innovation of Pol II-driven shRNA constructs built on miRNA backbones (Silva et al. 2005; Ni et al. 2011). In concept, artificial silencing constructs that are modeled on endogenous substrates are advantageous in that they mature effectively and are less likely to be seen as a foreign genetic material. Still, the precise features of highly effective shRNAs remain to be fully understood (Fellmann et al. 2011).

We recently demonstrated that the mir-451 backbone is amenable to reprogramming to yield diverse functional miRNAs from plasmid expression vectors (Yang et al. 2010). With the goal of developing this system for gene silencing, we performed structure-function studies to define critical parameters for Dicer-independent miRNA biogenesis. These experiments provide a rational basis for efficient reprogramming of Dicer-independent miRNA hairpins, provide unexpected insights into the maturation of conventional shRNAs, and highlight the dynamic status of different Ago2 cargoes.

\section{RESULTS}

\section{Functional requirement for most, but not all, pre-mir-451 hairpin base pairs}

Slicing of the pre-mir-451 hairpin by Ago2 is absolutely required for its maturation. We observed that point muta- tions that introduce bulged nucleotides at the tenth and eleventh positions across from the $5^{\prime}$ end of pre-mir-451 abrogate its cleavage, thus arresting its biogenesis at the hairpin stage (Yang et al. 2010). We investigated this further by systematically assessing the requirement for base-pairing along the pre-mir-451 stem, within the context of a functional human pri-mir-144/mir-451 expression construct. Scanning mutagenesis of its $3 \mathrm{p}$ arm (Fig. 1A) revealed that additional unpaired positions could be introduced at either the terminal loop (23A and 24C mutants) or the hairpin base (39G mutant), without strongly compromising its activity on a perfect sensor (Fig. 1B). On the other hand, unpaired positions elsewhere on the stem generally impaired its activity severalfold. In general, these changes in function correlated with accumulation of the pre-miRNA hairpin and loss of $\leq 30$-nt miR-451 species (Fig. 1C). Therefore, a high degree of hairpin structure is required for maturation of short hairpins loaded into Ago2. Unpairing at positions +36-38 also compromised accumulation of the pre-miRNA, potentially reflecting impaired cleavage by the Drosha/DGCR8 complex.

Notably, however, we observed that unpairing at +35 was well-tolerated for both biogenesis and function of $\mathrm{miR}$ 451 (Fig. 1B,C). The adjacent 5 '-nucleotides (34C and 33C mutants) were tolerant of unpairing, although to a lesser extent. Curiously, unpairing of the adjacent 3 '-nucleotides (36U and 37U) was strongly detrimental for miR-451 biogenesis and activity. As a control to these experiments, we blotted for miR-144 and observed no change in its mature levels in any of the variant constructs (Fig. 1C). Therefore, these biogenesis effects are autonomous to the mir-451 hairpin.

\section{Unpairing at the +35 position enhances miR-451 function}

We were struck by the functionality of the 35G mutant. Curiously, while pre-mir-451 has been highly conserved during vertebrate evolution, one nucleotide on the $3 \mathrm{p}$ arm is highly evolutionary labile (Fig. 2A) and is not even preserved among primates (e.g., between human and rhesus). This nucleotide is, indeed, position 35 of pre-mir-451, which adopts several identities resulting in both paired and unpaired configurations in different species (G:U/C/G). The collected biogenesis studies on the human (U), mouse (C), and zebrafish (G) orthologs provided evidence that all of these variants are compatible with endogenous miR-451 function (Cheloufi et al. 2010; Cifuentes et al. 2010; Yang et al. 2010).

Taking note of the fact that adenine is avoided at the hypervariable position in mir-451 orthologs, we introduced this residue to generate a G-A mispair and compared it with the $\mathrm{G}-\mathrm{G}$ variant and the wild-type non-canonical $\mathrm{G}-\mathrm{U}$ pair at position +35 (Fig. 2B). All of these mutants were well-processed in both HeLa cells and Dicer ${ }^{-1-}$ MEFs 


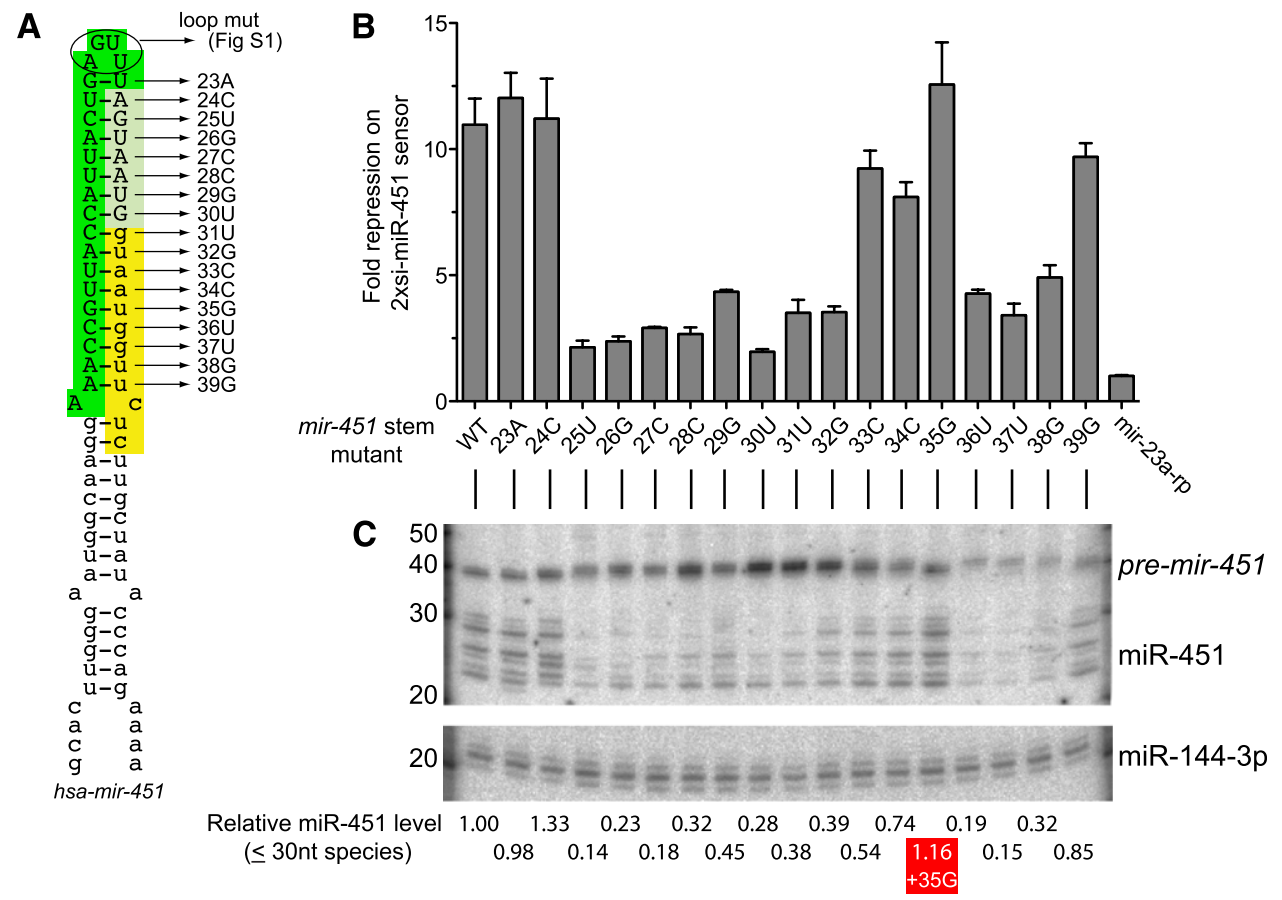

FIGURE 1. Systematic mutational analysis of pre-mir-451. (A) Schematic of the human pri-mir-451 hairpin used for mutagenesis within a previously described mir-451-mir-144 operon construct (Yang et al. 2010). The pre-mir-451 hairpin is shaded to denote the Ago2-cleaved byproduct (yellow), the resected region following Ago2 cleavage (light green), and the mature miR-451 product (dark green). The mutants are designated by their positions within the pre-mir-451 hairpin and the nucleotides to which they were changed. (B) Activity of mutant mir-451 constructs in HeLa cells, assayed on a Renilla luciferase construct bearing two antisense matches to mature miR-451. Sensor values were normalized to the level observed in cells transfected with a functional mir-451 variant reprogrammed with the miR-23a sequence (Yang et al. 2010). (C) Northern blot analysis of variant mir-451 constructs. The blot was probed for mature miR-451, which detects the hairpin (42 nt), Ago2-cleaved (30 nt), and resected species (23-30 nt). The blot was stripped and reprobed for miR-144 produced from the same construct. The relative levels of total $\leq 30 \mathrm{nt}$ miR-451 species were normalized to mature miR-144-3p. Note that mispairing caused by the $35 \mathrm{G}$ mutation was compatible with the biogenesis and function of miR-451, with levels slightly higher than the corresponding wild-type construct.

(Fig. 2C). It appeared that both unpaired mutants were resected more efficiently in HeLa cells, because they accumulated less 30-mer and slightly more 23-mer. The differences were not as apparent in Dicer $^{-1-}$ cells, which exhibited an altered resection pattern. Nevertheless, both "G:G" and "G:A" unpaired variants exhibited detectably greater activity than the wild-type construct, in both HeLa and Dicer $^{-1-}$ cells (Fig. 2D). Therefore, even though strong hairpin character is required for Dicer-independent biogenesis, unpairing at the +35 position is not only tolerated, but even enhances activity.

\section{Specific terminal loop nucleotides are not essential for mir-451 biogenesis}

An unusual aspect of mir-451 evolution, relative to all other conserved miRNA genes, is the much greater constraint in its terminal loop relative to its $3^{\prime}$ hairpin arm (Lai et al. 2003; Yang et al. 2010). Indeed, the $4 \mathrm{nt}$ comprising its terminal loop (AGUU) has been maintained among diverse vertebrates ranging from human to fish (Fig. 2A). We tested whether the strictly maintained terminal loop was required for miR-451 biogenesis by mutating all four loop nucleotides (loop-replaced), or adding an additional loop nucleotide (loop-extended). We observed that both loop mutants retained strong capacity to repress sensors (Supplemental Fig. 1). Therefore, the strictly conserved terminal loop does not provide essential information for miR-451 maturation.

\section{The influence of the $5^{\prime}$-nucleotide of pre-mir-451 on its biogenesis and activity}

Argonaute sorting in Drosophila routes different small RNAs to specific Ago proteins on the basis of internal duplex structure and the $5^{\prime}$-nucleotide (Tomari et al. 2007; Czech et al. 2009; Okamura et al. 2009; Ghildiyal et al. 2010). Mammalian Ago2 exhibits clear preference for $5^{\prime}$ uridine and adenine over cytosine or guanine, suggesting the possibility of sorting based on the $5^{\prime}$-nucleotide (Frank et al. 2010). However, substantial Ago sorting has not been described in vertebrate systems, since most miRNAs appear to accumulate relatively evenly among the Ago 1-4 proteins, even among miRNAs with different 5 '-nucleotides (Liu et al. 2004; Meister et al. 2004).

miR-451 is in the minority of miRNAs that do not begin with $5^{\prime}$ uridine; however, its initiating $5^{\prime}$ adenine is by no 


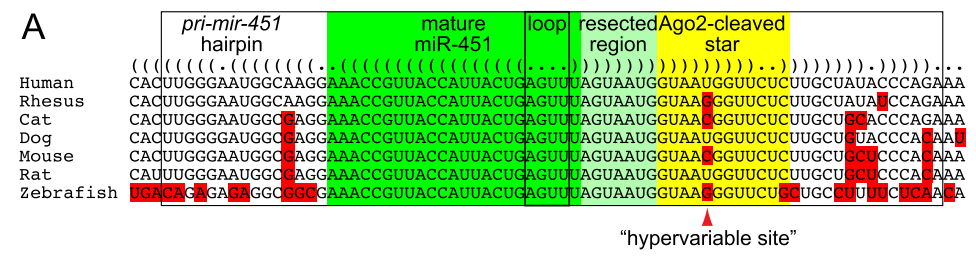

B
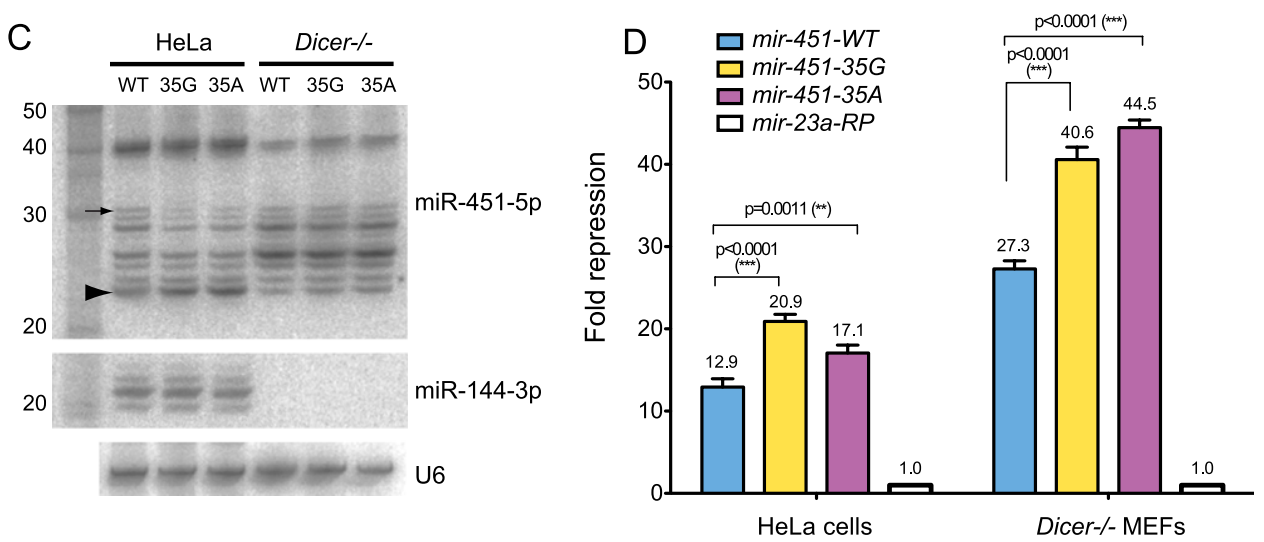

FIGURE 2. Mutational analysis of the mir-451 hypervariable stem position. (A) Sequence alignment of selected mir-451 orthologs. These emphasize strict conservation of mature miR-451 and the $3^{\prime}$ resected region, from man to fish, as well as divergence in the pri-miRNA lower stem (highlighted by red boxes). Note also that one position on the $3^{\prime}$ hairpin arm is highly variable during evolution, creating both paired and unpaired configurations; the specific nucleotide in human is not even preserved in rhesus. (B) Hypervariable site mutants that change the 35U found in wild-type human to $35 \mathrm{G}$ or $35 \mathrm{~A}$. (C) Processing of hypervariable site mutants in HeLa cells and Dicer ${ }^{-1-}$ MEFs. The 35G and 35A mutants accumulated slightly less ac-pre-miRNA (arrow) and slightly more mature miR-451 (arrowhead) than the wild-type construct. The banding patterns were not as substantially altered in the absence of Dicer; the lack of mature miR-144 confirms the genotype. $(D)$ When tested on sensors bearing two perfect miR-451 sites, the hypervariable site mutants were detectably more active than normal human mir-451. All errors represent SEM; a Student's two-tailed $t$-test was performed.

means unique among mammalian miRNAs. We systematically tested the influence of the $5^{\prime}$-nucleotide of miR-451 using variant constructs (Fig. 3A). In fact, variant miR-451 molecules bearing $5^{\prime}-\mathrm{U}, \mathrm{G}$, or $\mathrm{C}$ were all processed into typical miRNA-sized species (Fig. 3B). Therefore, the $5^{\prime}$ nucleotide of pre-mir-451 is not strictly required for its biogenesis. We did notice, however, that mutation of $5^{\prime}-\mathrm{A}$ to $G$ substantially impaired the accumulation of matured forms of miR-451 (Fig. 3B). This mutation introduces a novel G:C base pair at the base of the pre-mir-451 stem. We dissociated the effects of $5^{\prime}-\mathrm{G}$ and base-pairing at the +1 position by introducing a companion change on the $3^{\prime}$ end of the hairpin ( $\mathrm{G}-\mathrm{A}$ variant). This version was wellprocessed, indicating that the $\mathrm{G}-\mathrm{C}$ variant is impaired for structural reasons. We note, however, that the G-C variant exhibited only a mild decrease in accumulation of premiRNA. Therefore, even though in vitro assays showed local unpairing to be important for facilitating Drosha cleavage (Han et al. 2006), unpairing of the pre-mir-451 hairpin base may promote efficient maturation downstream from Drosha cleavage.

Although all four $5^{\prime}$-nucleotides were compatible with miR-451 biogenesis, the maturation efficiency of the $5^{\prime}-\mathrm{C}$ and $5^{\prime}-\mathrm{G}(\mathrm{G}-\mathrm{A})$ variants appeared slightly reduced relative to the $5^{\prime}-\mathrm{A}$ and $5^{\prime}-\mathrm{U}$ variants (Fig. 3B). We therefore evaluated a possible quantitative effect on miR-451 activity using sensor assays. We assayed the panel of $5^{\prime}$ miR-451 variants on perfect and bulged sensors in HeLa cells and observed that their relative activities could be ordered as $5^{\prime}-\mathrm{U}>\mathrm{A}>\mathrm{C}=\mathrm{G}$ (Fig. $3 \mathrm{C}$ ). The $5^{\prime}-\mathrm{U}$ variant was also the most effective of these variants when tested in Dicer $^{-1-}$ cells (Supplemental Fig. 2). Therefore, even though all known mir-451 orthologs exhibit 5'-A (e.g., Fig. 2A), its activity can be potentiated by substituting for $5^{\prime}-\mathrm{U}$.

\section{Stoichiometry of Ago proteins affects maturation of miR-451}

Previous studies indicated that pre-mir-451 can be loaded to both Ago1 and Ago2, but that Agol cannot mature it further owing to its lack of catalytic activity (Cheloufi et al. 2010; Yang et al. 2010). We tested the other 5'nucleotide variants and observed that Ago2 immunoprecipitates contained matured miR-451 species regardless of 5 '-nucleotide identity (Fig. 3D). On the other hand, Agol effectively loaded all four variants, but these were universally arrested as pre-mir-451 hairpins (Fig. 3D). We further tested the capacity of Ago3 to load pre-mir-451 by cotransfecting the pri-mir-144/mir-451 expression construct with tagged Ago3. Immunoprecipitation of Ago3 

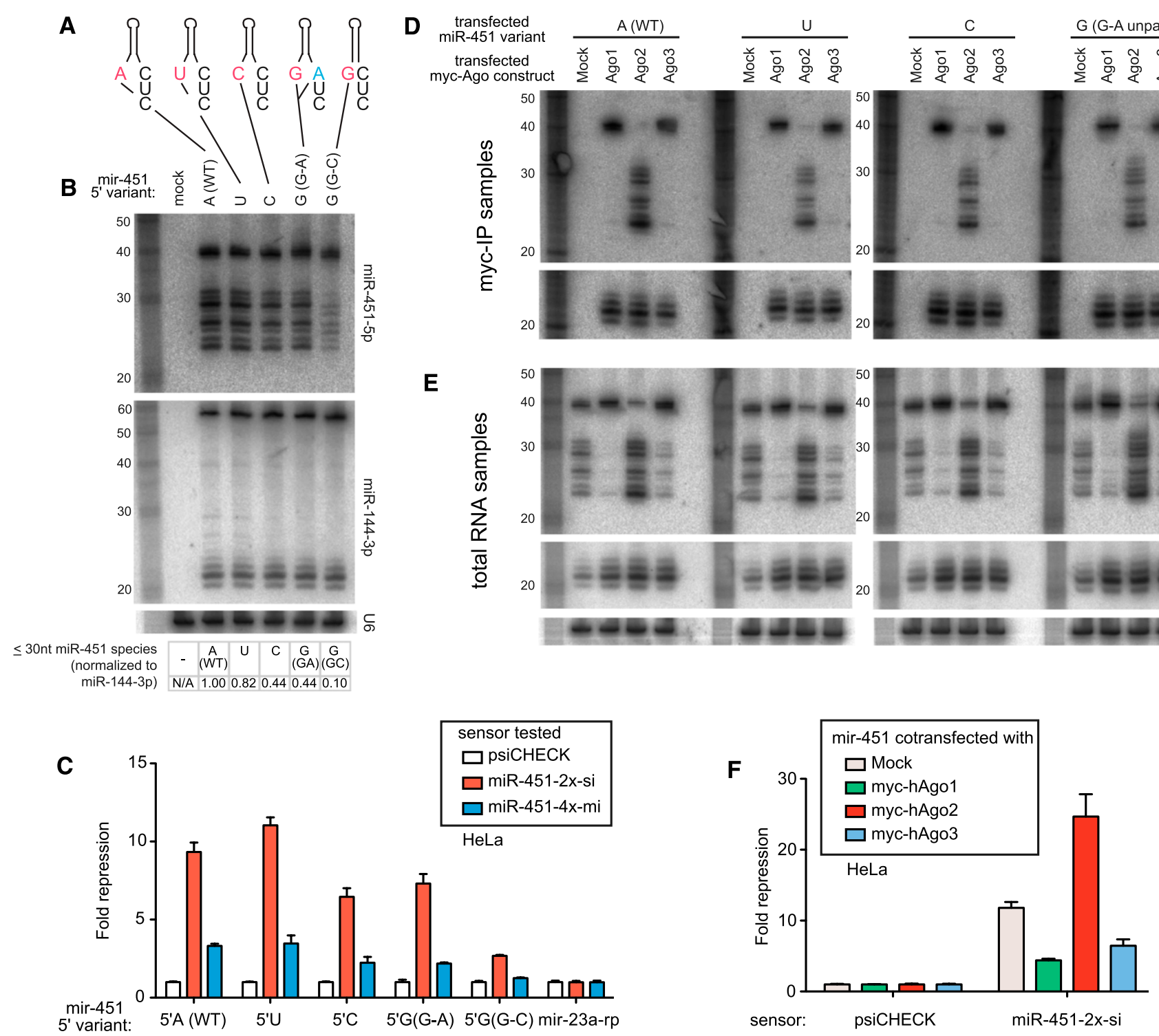

FIGURE 3. Influence of $5^{\prime}$-nucleotide and Ago protein levels on miR-451 biogenesis. (A) $5^{\prime}$-Nucleotide variants. The pre-mir-451 hairpin normally begins with $A$, which was altered to $5^{\prime}-\mathrm{U} / \mathrm{C} / \mathrm{G}$. Mutation to $5^{\prime}-\mathrm{G}$ alone generates a base pair with the terminal $\mathrm{C}(\mathrm{G}-\mathrm{C})$; therefore, we also made a $5^{\prime}-\mathrm{G}$ variant that is unpaired $(\mathrm{G}-\mathrm{A})$. (B) Maturation of the $5^{\prime}$ variants in HeLa cells. All of the $5^{\prime}$ variants that were unpaired at the +1 position were efficiently matured, although the $5^{\prime}-\mathrm{C}$ and $5^{\prime}-\mathrm{G}$ variants were processed less efficiently. Pairing at +1 ( $5^{\prime}-\mathrm{G}$, G-C) strongly diminished accumulation of cleaved and resected forms. Quantification is the level of total $\leq 30$-nt miR-451 species normalized to mature miR144-3p. (C) Activity of $5^{\prime}$ variants on perfect (" $2 \mathrm{x}$-si") and bulged (" $4 \mathrm{x}$-mi") sensors showed that their activities paralleled the maturation efficiency judged from Northern blotting. (D) Analysis of mir-451 5' variants in HeLa cells cotransfected with myc-Ago 1/2/3. Ago-IP analysis indicates that Ago2 associates exclusively with cleaved and $3^{\prime}$ resected species from all four 5' variants, whereas Agol and Ago3 associate exclusively with the pre-mir-451 hairpin of all four 5' variants. All Ago proteins associated equally with mature miR-144. (E) Analysis of companion total RNA samples indicates distinct effects of ectopic Ago proteins on miR-451 and miR-144. Maturation of all 5' variants was enhanced by elevated Ago2, but uniformly inhibited by elevation of either Ago1 or Ago3. Expression of Ago1/2/3 increased the levels of mature miR-144 in all cases. $(F)$ Functional consequences of Ago competition on miR-451 function. Repression of a miR-451 perfect sensor was enhanced by coexpression of Ago2, and inhibited by coexpression of Ago1 or Ago3.

showed that it associated almost exclusively with pre-mir451, and almost no mature miR-451 (Fig. 3D). As with Ago1, Ago3 could load all four 5' -nucleotide variants but could not mature any of them. Therefore, multiple Ago proteins can load short hairpins, but further maturation definitively requires Slicer activity.
Since pre-mir-451 is not selectively loaded to Ago2, we wondered whether the relative levels of Ago proteins might influence biogenesis of miR-451. We tested this by examining total RNAs across the panel of four $5^{\prime}$-nucleotide premir-451 variants cotransfected with tagged Ago1, Ago2, and Ago3. Analysis of the input samples reported on the 
influence of ectopic Ago proteins on bulk miRNA maturation. Consistent with previous results (Diederichs and Haber 2007), transfection of Ago1, Ago2, and Ago3 all increased the steady-state level of the canonical miRNA miR-144 carried by the expression construct (Fig. 3E), suggesting that Ago proteins are limiting for miRNA accumulation. In contrast, while Ago2 increased the maturation of miR-451 relative to normal HeLa cells, ectopic Ago1 and Ago3 strongly prevented the appearance of both cleaved and resected forms of miR-451 in total RNA. These findings indicated competition for pre-mir-451, so that elevation of non-slicing Ago proteins can actively prevent maturation of miR-451.

Ago competition had functional consequences, since the introduction of ectopic Ago2 stimulated the repression of a perfect sensor by miR-451 in HeLa cells, whereas elevation of Ago1 or Ago3 inhibited its regulatory activity (Fig. 3F). Therefore, the stoichiometry of endogenous Ago proteins can influence the efficiency of the Dicer-independent miRNA biogenesis, as well as the functional activity of the resulting small RNAs.

\section{The degree of $\mathrm{G}: \mathrm{C}$ content in the $3^{\prime}$ resected region governs resection efficiency}

A central aspect of miR-451 biogenesis is the resection of the 3' duplexed region following Ago2 cleavage of the hairpin precursor. Our analysis of an initial series of reprogrammed mir-451 constructs revealed that some produced a ladder of <30-nt species, typical of endogenous mir-451, whereas others preferentially produced single bands that migrated closer to the expected ac-pre-miRNA length (Yang et al. 2010). We hypothesized that these variations might reflect differences in the efficiency of $3^{\prime}$ resection following Ago2-mediated hairpin cleavage.

We tested this notion by analyzing chimeric constructs based on mir-451 hairpins that had been reprogrammed to express miR-199a-3p (mir-199a-RP) or miR-375-3p (mir-375-RP) (Fig. 4A). The former expresses a ladder of maturing bands, whereas the latter predominantly expresses an $\sim 30$-nt product in HeLa cells (Fig. 4B). The same was true in Dicer $^{-1-}$ MEFs, except that the levels of matured products were greater (Fig. 4B), as we typically observe with Dicer-independent substrates. We then swapped the distal hairpin stems of these constructs, yielding the 5'-199a:375-3' and 5'-375:199a-3' constructs. These chimeras clearly revealed that a hairpin with the distal region of mir-199a and the hairpin base of mir-375 produced multiple bands, similar to mir-199a-RP. The converse hairpin containing only the distal region of mir-375 produced a single large band of nearly $30 \mathrm{nt}$, similar to mir375-RP (Fig. 4C). Again, these trends were recapitulated in Dicer $^{-1-}$ MEFs (Fig. 4C). As a confirmation of cell genotype, Dicer $^{-1-}$ MEFs were completely arrested for mir-144 biogenesis at the pre-miRNA stage as expected (Fig. 4B,C).
These experiments indicated that the sequence of the distal stem determines its resection pattern; however, they did not distinguish whether the change in the distal hairpin quality or the terminal loop sequence was responsible. Since mutation of the endogenous mir-451 terminal loop did not substantially alter its processing (Supplemental Fig. 1), we favored the hypothesis that some aspect of hairpin quality was the major determinant of resection pattern. We noticed that the mir-199a-RP and mir-375-RP constructs differ in their amount of $G$ :C pairing in their hairpin regions remaining following Ago2 cleavage. The former bears three $\mathrm{G}$ :C pairs and the latter six G:C pairs; by comparison, endogenous mir-451 contains two G:C pairs in this region. Further inspection of a panel of reprogrammed mir-451 constructs (Yang et al. 2010) revealed that hairpins with three or fewer G:C base pairs in this region usually produced ladders of shortened species, while those with four or more G:C base pairs typically did not.

When we plotted the number of G:C base pairs in the $3^{\prime}$ resected region against their repression capacity as measured in Dicer ${ }^{-1-}$ MEFs (Yang et al. 2010), we observed a correlation of lower $\mathrm{G}$ :C content in this region with enhanced activity (Supplemental Fig. 3). This correlation was less pronounced in HeLa cells; however, this panel of reprogrammed constructs differs in many qualities, of which the G:C content in the $3^{\prime}$ resected region was but one variable. It was therefore conceivable that the Dicer ${ }^{-1-}$ situation allowed for a purer comparison, not confounded by other issues of competing in a background of canonical miRNAs. Overall, these observations were suggestive that the $\mathrm{G}$ :C content of distal stems influences their resection following Ago2 cleavage.

We tested this directly by systematically mutagenizing the distal region of the mir-451 hairpin, which normally contains two $\mathrm{G}: \mathrm{C}$ in the resected region, to include three, four, five, or eight distal G:C pairs (Fig. 4D). The hairpin forms of highly G:C-rich variants were not detected as efficiently, probably due to their stable structures, as demonstrated in control hybridizations against synthetic oligonucleotides (Supplemental Fig. 4). However, the linear, Ago-cleaved, and resected species should be detected with comparable efficiency. These experiments showed that shortened resection products remained abundant with three to four G:C pairs, but declined substantially in the variants with five or eight G:C pairs (Fig. 4E). We further asked whether the efficiency of $3^{\prime}$ resection influences the activity of reprogrammed mir-451 constructs, using a miR-451 seed sensor that permits direct comparison across a panel of constructs. These tests showed that variants bearing increased G:C content in the resected region were increasingly impaired in their capacity to repress the sensor (Fig. 4F). These tests are consistent with the notion that the degree of $\mathrm{G}: \mathrm{C}$ content in the $3^{\prime}$ resected region governs the maturation efficiency of Ago2-mediated miRNA biogenesis. 

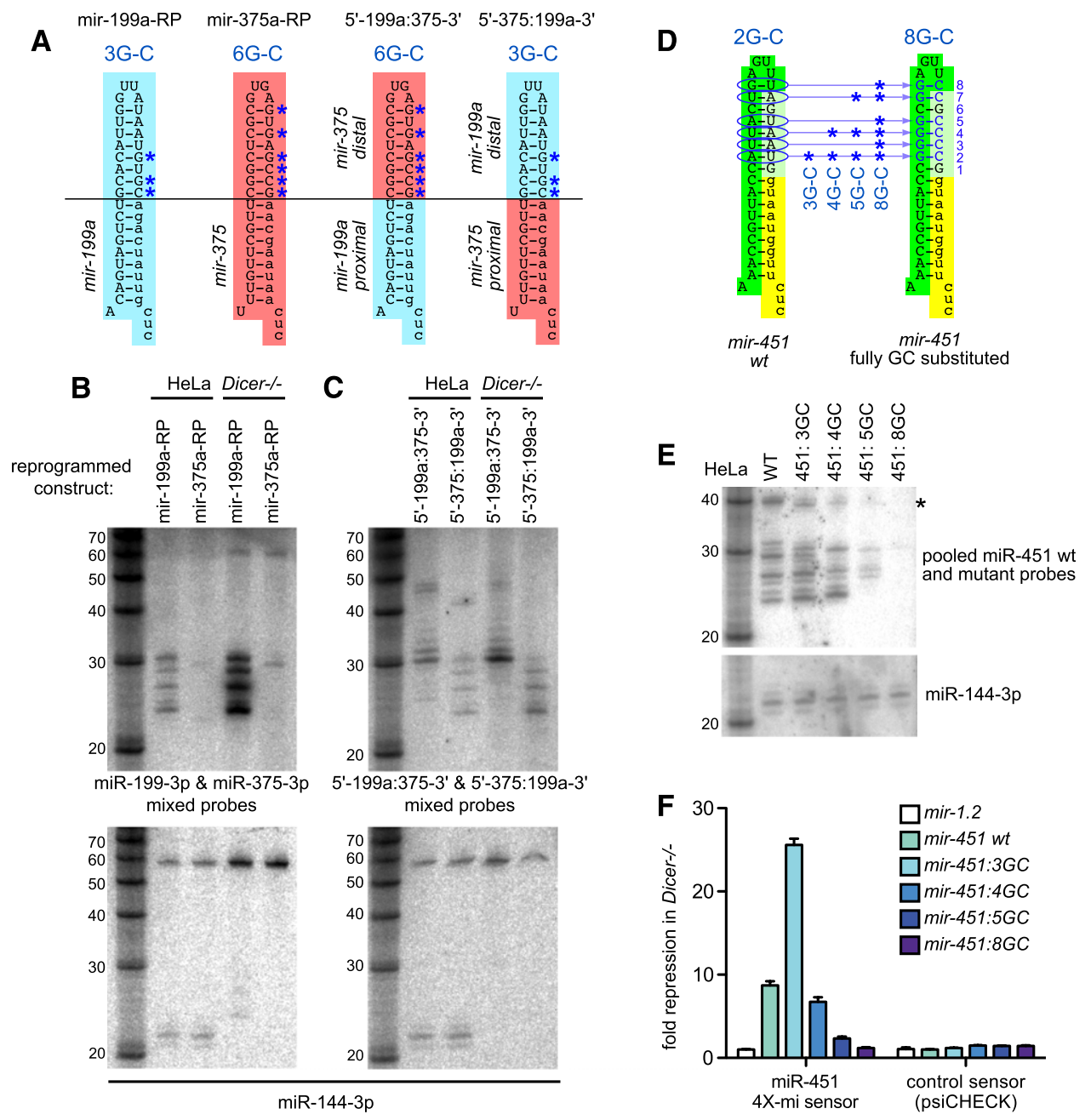

FIGURE 4. Influence of distal hairpin G:C content of $3^{\prime}$ resection efficiency. (A) mir-451 constructs reprogrammed with pre-mir-199a (mir199a-RP) or pre-mir-375 (mir-375-RP). These were compared with chimeric constructs in which the hairpin stem distal to the Ago 2 cleavage site (marked by the horizontal line) was exchanged. GC pairs in the resection region are marked with blue asterisks. $(B, C)$ Northern analysis of the wild-type and chimeric constructs in HeLa cell or Dicer ${ }^{-1-}$ MEFs. Similar patterns were observed in these cell lines except that expression of the mir-451-type constructs is higher in the absence of Dicer, whereas expression of the linked mir-144 is arrested at the pre-miRNA stage. The blots show that the $3^{\prime}$ resection pattern is correlated with the identity of the hairpin region distal to the Ago2 cleavage site; i.e., 5' $-375: 199 \mathrm{a}-3^{\prime}$ resembles miR-199a, while 5'-199a:375-3' resembles miR-375. (D) Direct manipulation of GC content in the human pre-mir-451 backbone. It normally contains two GCs in the $3^{\prime}$ resected region, and variant constructs sampled 3/4/5/8 GC pairs. (E) Northern analysis of the GC variant panel of mir451. Increase of distal GC content impairs generation of 3' resected forms of miR-451 in HeLa cells. The levels of Ago-cleaved and 3' resected forms of miR-451 are severely reduced with high GC content. $\left.{ }^{*}\right)$ The pre-mir-451, which appears to decrease with higher GC content. However, control experiments using oligonucleotide standards show that these high-GC-content hairpins are inefficiently detected; in contrast, the linear Ago-cleaved forms of these hairpins are detected with equal efficiency (Supplemental Fig. 4). Expression of miR-144 validates equal transfection and loading. $(F)$ Functional consequences of increased GC content on miR-451 function. These were tested in Dicer ${ }^{-1-}$ cells against a luciferase sensor bearing four seed matches for miR-451. The variants with the highest GC content in the $3^{\prime}$ resected region were severely impaired in their repression activity.

\section{Influence of hairpin length on direct Ago2 processing and Dicer cleavage}

Although the mir-451 locus has been very highly conserved during vertebrate evolution, the length of pre-mir-451 hairpins is not absolutely constant. For example, its loop region is $1 \mathrm{nt}$ longer in several fish species compared with land vertebrates (Yang et al. 2010). We therefore performed systematic tests to address whether modulation of mir-451 hairpin length affected its biogenesis (Fig. 5A). We compared the small RNA products produced from these length variants in $A g o 2^{-1-}$ cells supplemented with wild-type Ago2 (Ago2-WT) or catalytically dead Ago2 (Ago2-CD), as well as in Dicer $^{-1-}$ cells.

We observed that a variety of lengthened hairpins were competent to generate mature miR-451 (Fig. 5B). Given the variation seen in fish mir-451 orthologs, the biogenesis of hairpins lengthened by 2 or 3 bp was perhaps not too 

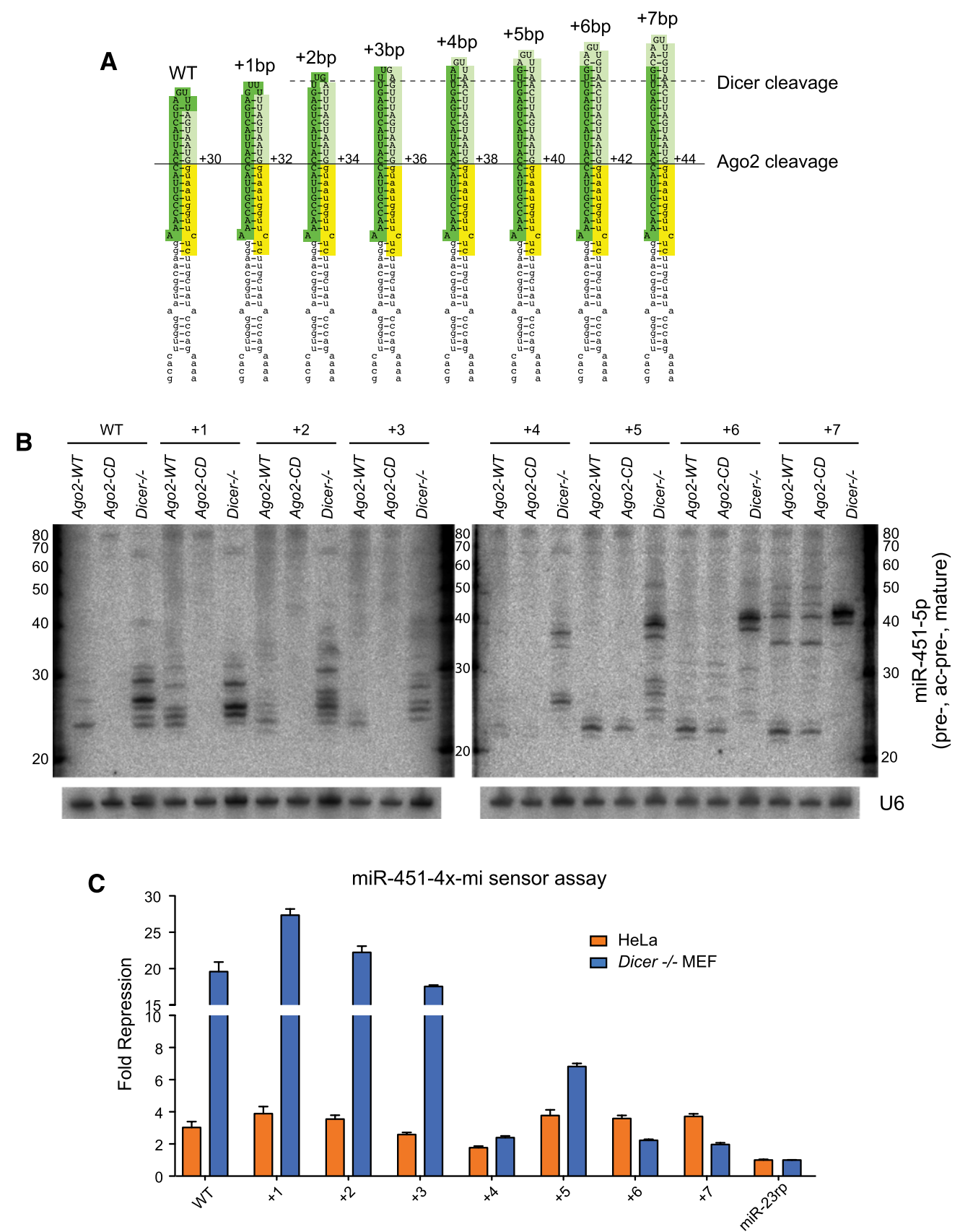

FIGURE 5. Influence of hairpin length on entry into the Ago2-dependent miRNA pathway. (A) The pre-mir-451 hairpin was extended by adding base pairs distal to the mature $23-n t$ miR-451 product (dark green box); thus, the sequence of mature miR-451 is not expected to change across this panel of length variants. Also highlighted are the inferred 12-nt 3' passenger strand resulting from Ago2 cleavage (yellow box) and the 3' resected region (light green box) following Ago2 cleavage. The solid reference line depicts the location of Ago2-mediated passenger strand cleavage; the dotted reference line depicts the putative location of 21-nt Dicer cleavage. $(B)$ Northern blot analysis of the depicted constructs in $\mathrm{Ago}^{-l-}$ MEFs reconstituted with wild-type Ago2 (Ago2-WT), with catalytic dead Ago2 (Ago2-CD), or in Dicer ${ }^{-l-}$ MEFs, using a mature miR451-5p probe in the common sequence of the panel of length variants. The blots were stripped and reprobed with U6 as a loading control. The absence of matured species in Ago2-CD cells for WT, $+1,+2$, and +3 constructs indicates that they are processed predominantly by the Ago2dependent pathway; this is substantiated by their processing in $\mathrm{Dicer}^{-1-}$ cells. With the +4 variant, a modest amount of Ago2-independent product appears and is enhanced in the $+5,+6$, and +7 constructs. This product is shorter than the predominant species detected in companion Dicer $^{-l-}$ cells, indicating that they are generated by distinct nucleases. The +5 variant is capable of maturing via both Ago2-dependent and Dicerdependent pathways. The +7 variant is strictly Dicer-dependent. $(C)$ Sensor assays of the length variant panel in HeLa cells and Dicer ${ }^{-1-}$ MEFs against a miR-451 luciferase sensor bearing four seed matches. The repression capacity of Ago2-dependent and Dicer-independent hairpins is relatively equivalent in HeLa cells, except for the +3 and +4 variants (which correlates with their lower efficiency of biogenesis, panel $B$ ). A subset of these hairpins is also active in Dicer ${ }^{-l-}$ MEFs, with shorter hairpin lengths exhibiting enhanced activity. 
surprising; however, constructs lengthened by 5-8 bp were also processed. The small RNA patterns generated across the panel of genetic backgrounds provided insight into the nature of biogenesis pathways. In particular, length variants of +1 to +3 were fully dependent on Slicer processing, because they were absent from Ago2-CD cells. On the other hand, length variants of +5 and greater produced mature small RNAs in Ago2-CD cells, suggesting that they were generated by the canonical Dicer-mediated pathway. This was further evident by the fact that the small RNAs produced in Dicer ${ }^{+}$cells (i.e., in $A g o 2^{-1-}$ cells reconstituted with either Ago2-WT or Ago2-CD) were slightly shorter and more homogeneous than those normally generated by mir451, consistent with RNase III-mediated cleavage.

Surprisingly, the fact that a substrate could be matured in a Slicer-independent fashion did not imply de facto that it was Dicer-dependent. For some variants, this was true; for example, the +7-bp stem extension matured in Ago2$C D$ cells and strictly accumulated the ac-pre-miRNA hairpin in Dicer $^{-1-}$ cells (Fig. 5B). The accumulation of the longer ac-pre-miRNA species in this condition may potentially reflect difficulty in unwinding an extended duplexed region following Ago2 cleavage. Therefore, Ago2 may preferentially mature shorter substrates. However, within the +4 -bp to +6 -bp range, we observed that the same hairpin substrate could transit both Slicer-dependent and Dicerdependent pathways. The +5 -bp variant, which bears a 22-bp stem, struck a balance for being relatively well-matured in both Ago2-CD cells and Dicer ${ }^{-1-}$ cells (Fig. 5B).

We tested the functional activities of this panel of constructs, and found them to be concordant with the Northern analyses (Fig. 5C). Here, we used multimerized miR-451 miRNA-type sensors so that we could directly compare the activity of the different pre-mir-451 variants. In HeLa cells, the Ago2-dependent and Dicer-dependent substrates were broadly of similar activity with the exception of the +4 length variant being weaker; it was also the least efficiently processed variant in Northern assays. In Dicer ${ }^{-1-}$ cells, the elevated function of Ago2dependent substrates became very apparent. This potentially reflected the loss of competition for Ago2 loading by canonical miRNA substrates, the converse of the Ago competition scenario observed in Figure 3, D and E. Finally, the +6 and +7 hairpin substrates were barely active in Dicer ${ }^{-1-}$ cells (Fig. 5C), corroborating the Northern analysis (Fig. 5B).

\section{Dicer-independent, Slicer-mediated maturation of conventional shRNA}

These length variation series demonstrated that hairpin stems of appropriate length are capable of maturing via both Dicer-dependent and Dicer-independent pathways (e.g., +5-bp \pm 1-bp stem variants). We noted that these lengths overlap the stem length typically utilized in shRNA constructs. It has been assumed that conventional shRNAs are fully Dicer-dependent, but to our knowledge this has not actually been widely tested.

We therefore examined this using a typically sized shRNA with a 5-nt loop and a 21-bp stem unrelated to mir-451 (Fig. 6A), expressed under control of RNA polymerase III. We expressed this shRNA in Ago $^{-1-}$ MEFs reconstituted with either wild-type Ago2 or catalytic-dead Ago2, as well as in Dicer ${ }^{-1-}$ MEFs. We detected accumu-

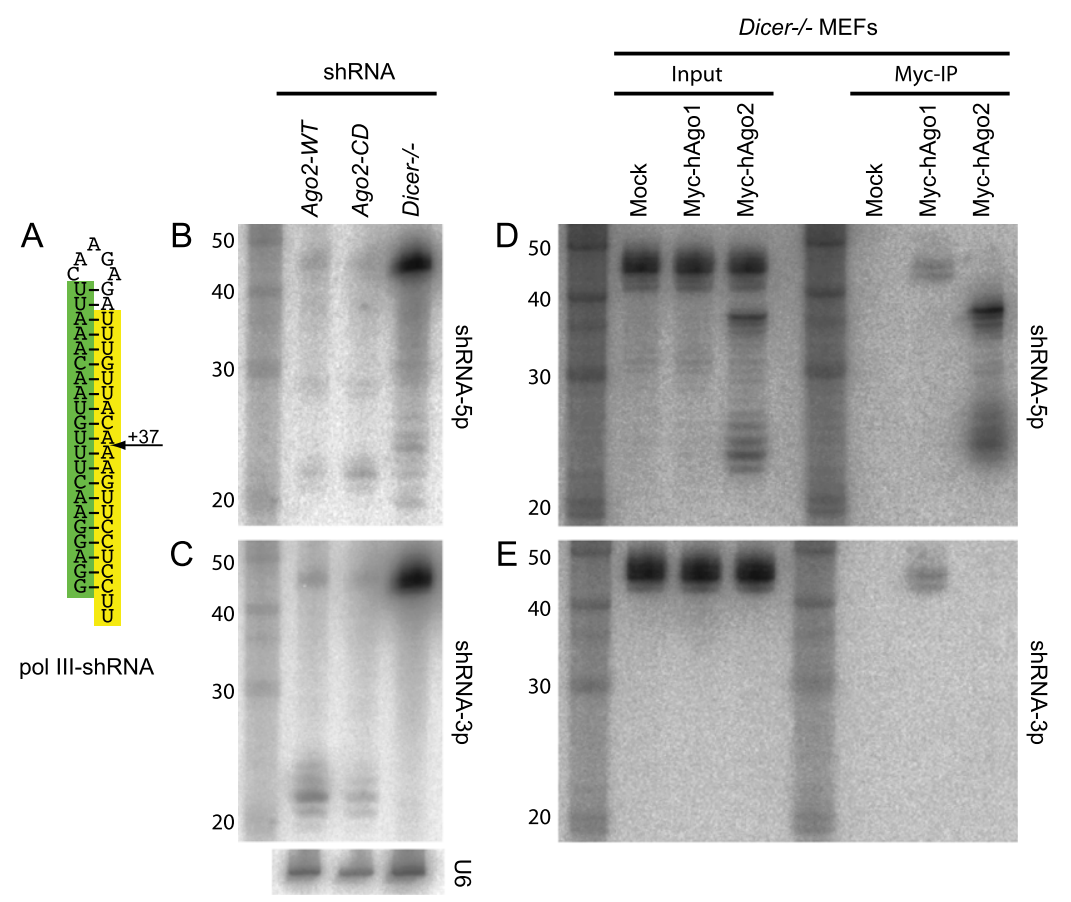

FIGURE 6. Maturation of a conventional shRNA through the Dicer-independent pathway. (A) Sequence of a conventional Pol III shRNA bearing a 21-bp stem and a 5-nt loop. The position of Ago2-mediated cleavage, if it occurs, is predicted to be at +37 from the $5^{\prime}$ end. $(B, C)$ Expression of the shRNA in $\mathrm{Ago}^{-l-}$ MEFs reconstituted with wild-type Ago2 (Ago2WT) or with catalytic dead Ago2 (Ago2-CD), or in $\mathrm{Dicer}^{-1-}$ MEFs. Small RNA products from both hairpin arms are detected in Ago2-WT and Ago2-CD cells; the shRNA hairpin is also detected at a low level. The hairpin accumulates to a high level in $\operatorname{Dicer}^{-1-}$ cells, which also accumulate a heterogeneous set of $<30$-nt products detected with a $5 \mathrm{p}$ arm probe, but not the $3 \mathrm{p}$ arm probe. $(D, E)$ Sorting and processing of shRNA-derived small RNAs in Dicer ${ }^{-1-}$ cells cotransfected with tagged hAgol or hAgo2. In total RNA from the input samples, the $\sim 37$-nt Ago-cleaved hairpin and $\sim 23-n t$ to $27-n t 3^{\prime}$ resected species are detected with the $5 \mathrm{p}$ probe $(D)$, but the $3 \mathrm{p}$ probe detects only the full-length shRNA hairpin $(E)$. The hAgol-IP samples contain only the full-length shRNA hairpin that is codetected by $5 p$ and $3 p$ probes, but hAgo2IP samples contain the Ago-cleaved and 3' resected mature species. 
lation of mature siRNAs from both $5 \mathrm{p}$ and $3 \mathrm{p}$ arms in Dicer $^{+}$cells, irrespective of Slicer status (Fig. 6B,C). In contrast, when tested in the absence of Dicer, both probes detected a strongly accumulated pre-shRNA hairpin. However, a probe against the $5 \mathrm{p}$ product also detected a series of shorter bands (Fig. 6B), whereas none were detected with the $3 p$ probe (Fig. $6 \mathrm{C}$ ). These banding patterns were reminiscent of Slicer-mediated banding patterns of miR-451 and its derivatives.

We tested whether this was the case by transfecting Dicer $^{-1-}$ cells with the shRNA and either myc-Agol and myc-Ago2, immunoprecipitating for Ago proteins, and probing for shRNA-derived species. As observed with mir-451, overexpression of Ago2 enhanced the biogenesis of the shRNA via the Slicer-dependent pathway, since we could clearly observe the presence of the 37-nt Ago-cleaved shRNA-5p species as well as a series of $<30$-nt bands even in input total RNA samples (Fig. 6D). IP analysis showed that Agol complexes contained only the full-length shRNA hairpin, which was detected with both $5 p$ and $3 p$ probes (Fig. 6D,E). On the other hand, Ago2 lacked reactivity to the hairpin, but carried the Ago-cleaved shRNA-5p species and its resected derivatives (Fig. 6D). Finally, we observed that Ago2 lacked reactivity to the $3 \mathrm{p}$ arm of shRNA (Fig. 6E), as predicted if it, in fact, cleaved this arm in the process of generating mature siRNAs. These findings indicate that despite the predominant processing of conventional shRNAs by Dicer, they are nonetheless capable of transiting the Slicer-mediated pathway, especially in the absence of the Dicer-mediated pathway.

\section{DISCUSSION}

\section{Dicer-mediated versus Ago2-mediated miRNA biogenesis}

Since Dicer is generally considered essential for the biogenesis of miRNAs and siRNAs, the elucidation of a wellconserved, Dicer-independent miRNA in vertebrates came as a surprise (Cheloufi et al. 2010; Cifuentes et al. 2010; Yang et al. 2010). These findings echo other recent studies of Dicer-independent miRNAs and siRNAs in fungi (Halic and Moazed 2010; Lee et al. 2010) and the fact that animal piRNAs (Ruby et al. 2006; Vagin et al. 2006) and Caenorhabditis elegans secondary siRNAs (Pak and Fire 2007; Sijen et al. 2007) are independent of RNase III enzymes. However, a unique feature of the mir-451 pathway is that Ago2 is not only the recipient of the small RNA produced by other enzymes, but its slicing activity is a prerequisite for additional maturation steps. In this sense, it is somewhat reminiscent of piRNA "ping-pong," where the slicer activity of Piwi proteins defines the piRNA 5' end and permits $3^{\prime}$ end generation (Brennecke et al. 2007; Gunawardane et al. 2007).

In light of similarities between Dicer- and Slicer-mediated miRNA biogenesis in animal cells_-both utilize short
RNA hairpins cropped by Drosha/DGCR8 - their distinctions are worth noting. For example, the broad flexibility in 5 '-nucleotide identity for mir-451 biogenesis was unexpected. By comparison, the $5^{\prime}$-uridine of let-7 was reported to be required for the ability of the miRNA-Ago2 complex to recruit mRNA targets for cleavage (Felice et al. 2009), and human Ago2 strongly disfavors 5' -cytosine or guanine as guide RNAs (Frank et al. 2010). In contrast, all four 5' nucleotides were relatively equally capable of maturing and loading as pre-mir-451 hairpins, with a detectable although not overwhelming functional advantage to the 5 ' - U variant. This may suggest distinctions in the recognition of hairpins and small RNAs by Ago2.

Our studies also reveal an unappreciated competition for substrates among Ago proteins (Fig. 3) and between Dicer and Ago (Fig. 5). With regard to the first point, we find that Ago1 and Ago3 can actively load pre-mir-451 but cannot mature it further owing to their lack of catalytic capacity. This induces a type of functional sorting in that only Ago2 can be populated with mature, active miR-451. Therefore, elevated stoichiometry of non-slicing Ago proteins can actively inhibit maturation of miR-451-type substrates. With regard to the second point, although Ago proteins are most well-known for loading short RNA duplexes, Ago2 has been reported to cleave pre-miRNA hairpins to some extent (Diederichs and Haber 2007). Moreover, loading of pre-miRNA hairpins into Ago2 is strongly enhanced in the absence of Dicer (Tan et al. 2009). These findings indicate that pre-miRNA hairpins are not exclusively routed to Dicer. We characterized the interplay between the acceptance of hairpin substrates by these two pathways, starting from the general notion that short hairpins such as pre-mir-451 are not Dicer substrates, while canonical pre-miRNA hairpins are preferred Dicer substrates. By systematically lengthening the pre-mir-451 stem, we identified a midpoint at which hairpins are capable of traversing both pathways. Such bifunctional intermediates may provide a useful starting point in studying the routing mechanisms and the nature of competition between Dicer and Argonaute proteins for cellular RNA hairpins.

\section{Rational design of mir-451-based silencing constructs}

The mir-451 backbone can be reprogrammed to generate other regulatory RNAs, not only in the context of synthetic RNA hairpins (Cheloufi et al. 2010; Cifuentes et al. 2010) but also from plasmid constructs (Yang et al. 2010). Therefore, mir-451 provides an alternative to using shRNA or sh-miR constructs. In principle, there are theoretical advantages to using mir-451-type constructs. They contain less dsRNA than other silencing triggers, thus they should evade PKR-mediated defense. Because mir-451 does not mature via Dicer, it does not compete with this aspect of canonical miRNA biogenesis. Perhaps most salient are the facts that mir-451 lacks a "star" strand and matures 
strictly within Ago2-Slicer. Star species have substantial regulatory impact (Okamura et al. 2008; Yang et al. 2011), and while knowledge of thermodynamic asymmetry can improve strand-selective loading (Khvorova et al. 2003; Schwarz et al. 2003), the mir-451 system simply eliminates the star strand. As for Ago selectivity, while Drosophila Ago proteins sort different cargoes, mammalian Ago proteins do not broadly implement sorting since most miRNAs load all four mammalian Agos (Liu et al. 2004; Meister et al. 2004). A major source of undesired "offtarget" effects of designed siRNAs result from seedmatched targets that mimic miRNA regulation (Jackson et al. 2003, 2006). Although pre-mir-451 is not sorted per se, its Slicer-dependent maturation means that its functional regulatory product does not populate Ago proteins that solely perform miRNA-type repression.

Our systematic structural analysis of mir-451 reveals several principles that maximize its activity and inform rational efforts to utilize this backbone as a silencing tool. For example, even though mir-451 orthologs all initiate with $5^{\prime}-A$, we found the $5^{\prime}-U$ variant to exhibit detectably increased activity (Fig. 3). In addition, while it might be assumed that a perfect hairpin is optimal for mir-451 activity, we found that unpairing at the pre-miRNA base is required for efficient processing and that specific unpairing at the +35 position is not only tolerated, but appears to potentiate its activity (Fig. 2). Augmentation of Ago2 levels also improves the activity of mir-451-type triggers, since non-slicing Ago proteins titrate available pre-mir-451 into non-functional complexes (Fig. 3). Finally, we demonstrate that the degree of G:C content in the distal duplexed region of ac-pre-mir-451 determines the efficacy of $3^{\prime}$ resection and resultant regulatory activity, such that a relatively low G:C content improves processing (Fig. 4). Altogether, this combination of features can be used to select appropriate target sites and hairpin structures for optimal Ago2-mediated biogenesis of designed siRNAs.

\section{MATERIALS AND METHODS}

\section{Generation of mutant hsa-mir-451-expressing constructs}

The wild-type hsa-mir-144/451 construct was previously described (Yang et al. 2010). mir-451 mutant sequences were cloned between two EcoRI sites of the pcDNA6.2/N-EmGFP TOPO vector (Invitrogen) using Cold Fusion Cloning Kit (System Biosciences). Briefly, oligonucleotides (Supplemental Table "primers") containing the mutant sites with $\sim 15$-nt upstream and downstream flanking sequences were used in combination with either the FP1 forward or TK-poly(A) reverse primer in a polymerase chain reaction (PCR) using the wild-type hsa-mir-144/451 plasmid as template. The resulting two PCR products that had an overlapping region were gel-purified and mixed with EcoRI-digested hsa-mir-144/451 plasmid. The cold fusion cloning reaction was then performed according to the manufacturer's manual.

\section{Cell culture and transfection}

HeLa cells and mutant MEFs (Yang et al. 2010) were grown in DMEM medium supplemented with 10\% heat-inactivated FBS and $1 \%$ Penicillin-Streptomycin (GIBCO) and incubated in a humidified $37^{\circ} \mathrm{C} / 5 \% \mathrm{CO}_{2}$ incubator. Lipofectamine 2000 reagent (Invitrogen) was used to transfect cells with different constructs according to the manufacturer's manual. Cells were harvested $24 \mathrm{~h}$ after transfection.

\section{Northern blotting}

Total RNA was extracted from cultured cells with TRIzol (Life Technologies). RNA samples were separated on $20 \%$ urea polyacrylamide denaturing gels (National Diagnostics), transferred to GeneScreen Plus (PerkinElmer), and probed with $\left[\gamma^{-32} \mathrm{P}\right]$-labeled DNA oligonucleotides antisense to the subjective miRNAs overnight at $45^{\circ} \mathrm{C}$. The membranes were washed with $2 \times \mathrm{SSC} / 0.1 \%$ SDS at $45^{\circ} \mathrm{C}$ four times, $15 \mathrm{~min}$ each time. Then the signals were exposed to Imaging Plate (Fujifilm). The sequences of the probes are listed in the Supplemental Table "Northern probes."

To analyze Ago-associated RNA, cells were cotransfected with Myc-tagged Ago constructs and miRNA-expressing constructs. Cell lysates were cleared and then incubated with Myc antibodyconjugated Dynabeads Protein G (Invitrogen). The Ago-associated RNA was extracted with phenol:chloroform:isoamyl alcohol (25:24:1), followed by ethanol precipitation overnight at $-20^{\circ} \mathrm{C}$. The RNA was analyzed as described above.

\section{Luciferase sensor assay}

The psiCHECK2 luciferase sensor constructs were generated as previously described (Okamura et al. 2007). HeLa and mutant MEFs were cotransfected with miRNA and sensor plasmids using Lipofectamine 2000 (Invitrogen). Twenty-four hours after transfection, luciferase activities were measured with the Dual-Glo Luciferase Assay System (Promega) following the manufacturer's instruction.

\section{SUPPLEMENTAL MATERIAL}

Supplemental material is available for this article.

\section{ACKNOWLEDGMENTS}

We thank Jidong Liu for providing tagged Ago plasmids and Alexander Tarakhovsky for Dicer and Ago2 mutant cells. J.-S.Y. was supported by a Frank Lappin Horsfall Jr. Student Fellowship. Work in E.C.L.'s group was supported by the Burroughs Wellcome Fund, the Starr Cancer Consortium (I3-A139), and the NIH (R01-GM083300).

Received February 16, 2012; accepted February 29, 2012.

\section{REFERENCES}

Babiarz JE, Ruby JG, Wang Y, Bartel DP, Blelloch R. 2008. Mouse ES cells express endogenous shRNAs, siRNAs, and other Microprocessor-independent, Dicer-dependent small RNAs. Genes Dev 22: 2773-2785. 
Bogerd HP, Karnowski HW, Cai X, Shin J, Pohlers M, Cullen BR. 2010. A mammalian herpesvirus uses noncanonical expression and processing mechanisms to generate viral microRNAs. Mol Cell 37: 135-142.

Brennecke J, Stark A, Russell RB, Cohen SM. 2005. Principles of microRNA-target recognition. PLoS Biol 3: e85. doi: 10.1371/ journal.pbio.0030085.

Brennecke J, Aravin AA, Stark A, Dus M, Kellis M, Sachidanandam R, Hannon GJ. 2007. Discrete small RNA-generating loci as master regulators of transposon activity in Drosophila. Cell 128: 10891103.

Brummelkamp TR, Bernards R, Agami R. 2002. A system for stable expression of short interfering RNAs in mammalian cells. Science 296: $550-553$.

Cazalla D, Xie M, Steitz JA. 2011. A primate herpesvirus uses the Integrator complex to generate viral microRNAs. Mol Cell 43: 982-992.

Cheloufi S, Dos Santos CO, Chong MM, Hannon GJ. 2010. A Dicerindependent miRNA biogenesis pathway that requires Ago catalysis. Nature 465: 584-589.

Cifuentes D, Xue H, Taylor DW, Patnode H, Mishima Y, Cheloufi S, Ma E, Mane S, Hannon GJ, Lawson N, et al. 2010. A novel miRNA processing pathway independent of Dicer requires Argonaute2 catalytic activity. Science 328: 1694-1698.

Czech B, Zhou R, Erlich Y, Brennecke J, Binari R, Villalta C, Gordon A, Perrimon N, Hannon GJ. 2009. Hierarchical rules for Argonaute loading in Drosophila. Mol Cell 36: 445-456.

Diederichs S, Haber DA. 2007. Dual role for Argonautes in microRNA processing and posttranscriptional regulation of microRNA expression. Cell 131: 1097-1108.

Elbashir SM, Harborth J, Lendeckel W, Yalcin A, Weber K, Tuschl T. 2001. Duplexes of 21-nucleotide RNAs mediate RNA interference in cultured mammalian cells. Nature 411: 494-498.

Ender C, Krek A, Friedlander MR, Beitzinger M, Weinmann L, Chen W, Pfeffer S, Rajewsky N, Meister G. 2008. A human snoRNA with microRNA-like functions. Mol Cell 32: 519-528.

Fabian MR, Sonenberg N, Filipowicz W. 2010. Regulation of mRNA translation and stability by microRNAs. Annu Rev Biochem 79: 351-379.

Felice KM, Salzman DW, Shubert-Coleman J, Jensen KP, Furneaux HM. 2009. The $5^{\prime}$ terminal uracil of let-7a is critical for the recruitment of mRNA to Argonaute2. Biochem J 422: 329-341.

Fellmann C, Zuber J, McJunkin K, Chang K, Malone CD, Dickins RA, Xu Q, Hengartner MO, Elledge SJ, Hannon GJ, et al. 2011. Functional identification of optimized RNAi triggers using a massively parallel sensor assay. Mol Cell 41: 733-746.

Fire A, Xu S, Montgomery MK, Kostas SA, Driver SE, Mello CC. 1998. Potent and specific genetic interference by double-stranded RNA in Caenorhabditis elegans. Nature 391: 806-811.

Flynt AS, Lai EC. 2008. Biological principles of microRNA-mediated regulation: shared themes amid diversity. Nat Rev Genet 9: 831842.

Flynt AS, Chung WJ, Greimann JC, Lima CD, Lai EC. 2010. microRNA biogenesis via splicing and exosome-mediated trimming in Drosophila. Mol Cell 38: 900-907.

Frank F, Sonenberg N, Nagar B. 2010. Structural basis for 5'nucleotide base-specific recognition of guide RNA by human AGO2. Nature 465: 818-822.

Ghildiyal M, Xu J, Seitz H, Weng Z, Zamore PD. 2010. Sorting of Drosophila small silencing RNAs partitions microRNA* strands into the RNA interference pathway. RNA 16: 43-56.

Giraldez AJ, Mishima Y, Rihel J, Grocock RJ, Van Dongen S, Inoue K, Enright AJ, Schier AF. 2006. Zebrafish MiR-430 promotes deadenylation and clearance of maternal mRNAs. Science 312: 75-79.

Grishok A, Pasquinelli A, Conte D, Li N, Parrish S, Ha I, Baillie DL, Fire A, Ruvkun G, Mello CC. 2001. Genes and mechanisms related to RNA interference regulate expression of the small temporal RNAs that control C. elegans developmental timing. Cell 106: $23-34$.
Gunawardane LS, Saito K, Nishida KM, Miyoshi K, Kawamura Y, Nagami T, Siomi H, Siomi MC. 2007. A slicer-mediated mechanism for repeat-associated siRNA $5^{\prime}$ end formation in Drosophila. Science 315: 1587-1590.

Guo H, Ingolia NT, Weissman JS, Bartel DP. 2010. Mammalian microRNAs predominantly act to decrease target mRNA levels. Nature 466: 835-840.

Halic M, Moazed D. 2010. Dicer-independent primal RNAs trigger RNAi and heterochromatin formation. Cell 140: 504-516.

Han J, Lee Y, Yeom KH, Nam JW, Heo I, Rhee JK, Sohn SY, Cho Y, Zhang BT, Kim VN. 2006. Molecular basis for the recognition of primary microRNAs by the Drosha-DGCR8 complex. Cell 125: 887-901.

Hutvagner G, McLachlan J, Pasquinelli A, Balint E, Tuschl T, Zamore PD. 2001. A cellular function for the RNA-interference enzyme Dicer in the maturation of the let-7 small temporal RNA. Science 293: 834-838.

Jackson AL, Bartz SR, Schelter J, Kobayashi SV, Burchard J, Mao M, Li B, Cavet G, Linsley PS. 2003. Expression profiling reveals off-target gene regulation by RNAi. Nat Biotechnol 21: 635-637.

Jackson AL, Burchard J, Schelter J, Chau BN, Cleary M, Lim L, Linsley PS. 2006. Widespread siRNA "off-target" transcript silencing mediated by seed region sequence complementarity. RNA 12: 1179-1187.

Ketting R, Fischer S, Bernstein E, Sijen T, Hannon G, Plasterk RH. 2001. Dicer functions in RNA interference and in synthesis of small RNAs involved in developmental timing in C. elegans. Genes Dev 15: 2654-2659.

Khvorova A, Reynolds A, Jayasena SD. 2003. Functional siRNAs and miRNAs exhibit strand bias. Cell 115: 209-216.

Knight S, Bass BL. 2001. A role for the RNAse III enzyme DCR-1 in RNA interference and germ line development in Caenorhabditis elegans. Science 293: 2269-2271.

Lai EC. 2002. microRNAs are complementary to $3^{\prime}$ UTR sequence motifs that mediate negative post-transcriptional regulation. Nat Genet 30: 363-364.

Lai EC. 2003. microRNAs: Runts of the genome assert themselves. Curr Biol 13: R925-R936.

Lai EC, Burks C, Posakony JW. 1998. The K box, a conserved 3' UTR sequence motif, negatively regulates accumulation of Enhancer of split Complex transcripts. Development 125: 4077-4088.

Lai EC, Tomancak P, Williams RW, Rubin GM. 2003. Computational identification of Drosophila microRNA genes. Genome Biol 4: R42.41-R42.20.

Lee RC, Feinbaum RL, Ambros V. 1993. The C. elegans heterochronic gene lin-4 encodes small RNAs with antisense complementarity to lin-14. Cell 75: 843-854.

Lee NS, Dohjima T, Bauer G, Li H, Li MJ, Ehsani A, Salvaterra P, Rossi J. 2002. Expression of small interfering RNAs targeted against HIV-1 rev transcripts in human cells. Nat Biotechnol 20: 500-505.

Lee Y, Ahn C, Han J, Choi H, Kim J, Yim J, Lee J, Provost P, Radmark O, Kim S, et al. 2003. The nuclear RNase III Drosha initiates microRNA processing. Nature 425: 415-419.

Lee HC, Li L, Gu W, Xue Z, Crosthwaite SK, Pertsemlidis A, Lewis ZA, Freitag M, Selker EU, Mello CC, et al. 2010. Diverse pathways generate microRNA-like RNAs and Dicer-independent small interfering RNAs in fungi. Mol Cell 38: 803-814.

Leuschner PJ, Ameres SL, Kueng S, Martinez J. 2006. Cleavage of the siRNA passenger strand during RISC assembly in human cells. EMBO Rep 7: 314-320.

Lewis BP, Shih IH, Jones-Rhoades MW, Bartel DP, Burge CB. 2003. Prediction of mammalian microRNA targets. Cell 115: 787-798.

Liu J, Carmell MA, Rivas FV, Marsden CG, Thomson JM, Song JJ, Hammond SM, Joshua-Tor L, Hannon GJ. 2004. Argonaute2 is the catalytic engine of mammalian RNAi. Science 305: 1437-1441.

Matranga C, Tomari Y, Shin C, Bartel DP, Zamore PD. 2005. Passenger-strand cleavage facilitates assembly of siRNA into Ago2containing RNAi enzyme complexes. Cell 123: 607-620. 
Meister G, Landthaler M, Patkaniowska A, Dorsett Y, Teng G, Tuschl T. 2004. Human Argonaute2 mediates RNA cleavage targeted by miRNAs and siRNAs. Mol Cell 15: 185-197.

Miyagishi M, Taira K. 2002. U6 promoter-driven siRNAs with four uridine $3^{\prime}$ overhangs efficiently suppress targeted gene expression in mammalian cells. Nat Biotechnol 20: 497-500.

Ni JQ, Zhou R, Czech B, Liu LP, Holderbaum L, Yang-Zhou D, Shim HS, Tao R, Handler D, Karpowicz P, et al. 2011. A genome-scale shRNA resource for transgenic RNAi in Drosophila. Nat Methods 8: 405-407.

Okamura K, Lai EC. 2008. Endogenous small interfering RNAs in animals. Nat Rev Mol Cell Biol 9: 673-678.

Okamura K, Hagen JW, Duan H, Tyler DM, Lai EC. 2007. The mirtron pathway generates microRNA-class regulatory RNAs in Drosophila. Cell 130: 89-100.

Okamura K, Phillips MD, Tyler DM, Duan H, Chou YT, Lai EC. 2008. The regulatory activity of microRNA* species has substantial influence on microRNA and $3^{\prime}$ UTR evolution. Nat Struct Mol Biol 15: 354-363.

Okamura K, Liu N, Lai EC. 2009. Distinct mechanisms for microRNA strand selection by Drosophila Argonautes. Mol Cell 36: 431444.

Paddison PJ, Caudy AA, Bernstein E, Hannon GJ, Conklin DS. 2002. Short hairpin RNAs (shRNAs) induce sequence-specific silencing in mammalian cells. Genes Dev 16: 948-958.

Pak J, Fire A. 2007. Distinct populations of primary and secondary effectors during RNAi in C. elegans. Science 315: 241-244.

Paul CP, Good PD, Winer I, Engelke DR. 2002. Effective expression of small interfering RNA in human cells. Nat Biotechnol 20: 505-508.

Rand TA, Petersen S, Du F, Wang X. 2005. Argonaute2 cleaves the anti-guide strand of siRNA during RISC activation. Cell 123: 621629.

Reinhart BJ, Slack F, Basson M, Pasquinelli A, Bettinger J, Rougvie A, Horvitz HR, Ruvkun G. 2000. The 21-nucleotide let-7 RNA regulates developmental timing in Caenorhabditis elegans. Nature 403: 901-906.

Ruby JG, Jan C, Player C, Axtell MJ, Lee W, Nusbaum C, Ge H, Bartel DP. 2006. Large-scale sequencing reveals 21U-RNAs and additional microRNAs and endogenous siRNAs in C. elegans. Cell 127: 1193-1207.
Ruby JG, Jan CH, Bartel DP. 2007. Intronic microRNA precursors that bypass Drosha processing. Nature 448: 83-86.

Schwarz DS, Hutvagner G, Du T, Xu Z, Aronin N, Zamore PD. 2003. Asymmetry in the assembly of the RNAi enzyme complex. Cell 115: 199-208.

Sijen T, Steiner FA, Thijssen KL, Plasterk RH. 2007. Secondary siRNAs result from unprimed RNA synthesis and form a distinct class. Science 315: 244-247.

Silva JM, Li MZ, Chang K, Ge W, Golding MC, Rickles RJ, Siolas D, Hu G, Paddison PJ, Schlabach MR, et al. 2005. Second-generation shRNA libraries covering the mouse and human genomes. Nat Genet 37: 1281-1288.

Sui G, Soohoo C, Affar EB, Gay F, Shi Y, Forrester WC. 2002. A DNA vector-based RNAi technology to suppress gene expression in mammalian cells. Proc Natl Acad Sci 99: 5515-5520.

Tan GS, Garchow BG, Liu X, Yeung J, Morris JP IV, Cuellar TL, McManus MT, Kiriakidou M. 2009. Expanded RNA-binding activities of mammalian Argonaute 2. Nucleic Acids Res 37: 7533-7545.

Tomari Y, Du T, Zamore PD. 2007. Sorting of Drosophila small silencing RNAs. Cell 130: 299-308.

Tuschl T, Zamore PD, Lehmann R, Bartel DP, Sharp PA. 1999. Targeted mRNA degradation by double-stranded RNA in vitro. Genes Dev 13: 3191-3197.

Vagin VV, Sigova A, Li C, Seitz H, Gvozdev V, Zamore PD. 2006. A distinct small RNA pathway silences selfish genetic elements in the germline. Science 313: 320-324.

Yang JS, Lai EC. 2011. Alternative miRNA biogenesis pathways and the interpretation of core miRNA pathway mutants. Mol Cell 43: 892-903.

Yang JS, Maurin T, Robine N, Rasmussen KD, Jeffrey KL, Chandwani R, Papapetrou EP, Sadelain M, O'Carroll D, Lai EC. 2010. Conserved vertebrate mir-451 provides a platform for Dicerindependent, Ago2-mediated microRNA biogenesis. Proc Natl Acad Sci 107: 15163-15168.

Yang JS, Phillips MD, Betel D, Mu P, Ventura A, Siepel AC, Chen KC, Lai EC. 2011. Widespread regulatory activity of vertebrate microRNA* species. RNA 17: 312-326.

Zamore PD, Tuschl T, Sharp PA, Bartel DP. 2000. RNAi: Doublestranded RNA directs the ATP-dependent cleavage of mRNA at 21 to 23 nucleotide intervals. Cell 101: 25-33. 

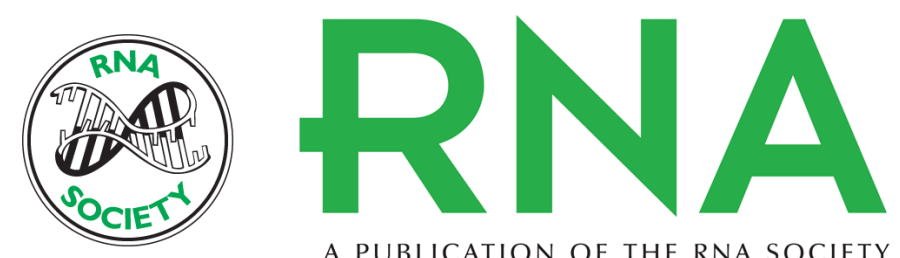

A PUBLICATION OF THE RNA SOCIETY

\section{Functional parameters of Dicer-independent microRNA biogenesis}

Jr-Shiuan Yang, Thomas Maurin and Eric C. Lai

RNA 2012 18: 945-957 originally published online March 29, 2012

Access the most recent version at doi:10.1261/rna.032938.112

Supplemental

Material

References

Open Access

License Freely available online through the RNA Open Access option.

http://rnajournal.cshlp.org/content/suppl/2012/03/14/rna.032938.112.DC1

This article cites 70 articles, 21 of which can be accessed free at: http://rnajournal.cshlp.org/content/18/5/945.full.html\#ref-list-1

Freely available online through the RNA Open Access option.

Email Alerting Service

Receive free email alerts when new articles cite this article - sign up in the box at the top right corner of the article or click here. 